\title{
Development of Automated Intravenous Blood Infusion Monitoring System using Load Cell Sensor
}

\author{
*1'AJIBOLA, OOE; ${ }^{2}$ SUNDAY, OO; ${ }^{2}$ EYEHORUA, DO \\ ${ }^{1}$ Department of Systems Engineering, ${ }^{2}$ Department of Biomedical Engineering, University of Lagos, Lagos, Nigeria \\ *Corresponding Author Email: waleisiro@yahoo.com; slinksjoy@gmail.com; daniella.eyeh@gmail.com
} Tel: +234-803-448-8877

\begin{abstract}
This paper presents an automated intravenous blood infusion unit to prevent a reflux using a load cell sensor. Intravenous infusion is frequently used in the hospital for patients' management and treatments such as dehydration and surgical operations. The sensor measures initial weight (500 mls) of initial content of intravenous bag and set a threshold of $20 \mathrm{mls}$ or less, and then sends a signal through transmitter to receiver as an alarm indicating current state of the intravenous infusion. This is to support monitoring system by biomedical professionals and avoid blood reflux. The sensor has a strain gauge transducer that converts force into an electric signal in millivolts; two-18 pin microcontroller was deplored to modulate signals from the transmitter to the receiver, a buzzer indicator for sound notification, and LCD display monitor screen node station.
\end{abstract}

\section{DOI: https://dx.doi.org/10.4314/jasem.v22i10.04}

Copyright: Copyright $(92018$ Ajibola et al. This is an open access article distributed under the Creative Commons Attribution License (CCL), which permits unrestricted use, distribution, and reproduction in any medium, provided the original work is properly cited.

Dates: Received: 18 May 2018; Revised: 20 July: 2018; Accepted: 03 October 2018

Keywords: Intravenous infusion, hospital information system, reflux, intravenous therapy.

Patient monitoring is defined as repeated or continuous observations of physiological parameters of the patient, and the function of life support equipment, for the purpose of guiding management decisions, including when to make therapeutic interventions, and assessment of those interventions (Ajibola et al, 2017; Priyadharshini.R, et al, 2015). One such area where patients' monitoring is most desired is drug administration using intravenous (IV) infusion. And it has been proven to be very effective for quick supply of prescribed medicines into the entire body. However, blood-reflux, air embolism, infection, damage of vessels are example of such possible complications of IV infusion (Iyile and Attah, 2016). Inappropriate IV fluid therapy is significant cause of patient morbidity and mortality and may result from either incorrect volume or type of fluid (Andrew et al., 2008). Generally, as the population grows, the need to improve on healthcare services becomes imperative translating to expansion of workforce with consequent higher personnel cost. And in almost all cases manpower requirement cannot be met by training and recruiment processes, hence the need for synergy between technology and health professionalism. This has spurred the deployment of enhanced technology to solving many healthcare problems. Relying on inadequate workforce may not sufficiently deliver the best of services, especially in areas with dearth of manpower or where paucity of funds has prevented manpower recruitment, thus employing expert health care systems. The call for evidence-based quality improvement and healthcare transformation underscores the need for redesigning care system that is effective, safe, and efficient (Stevens, 2013). Today, healthcare monitoring devices are deployed in health management services to ensure patients safety and to reduce the burden of the caregivers and health workers (Ajibola and Folorunso, 2017; Priyadharshini.R, et al, 2015). The novelty of these devices has brought about a characteristic change in the practice of medicine. Of primary concern in this study is the eradication of complications associated with application of intravenous administration of drug, blood, body electrolyte and metabolite by developing an automated alarm system that monitors IV infusion process and triggers an alarm when the infusion bag with content attains a preset threshold weight in real time.

\section{MATERIALS AND METHODS}

Materials: Components deplored are; $100 \Omega, 1 \mathrm{k} \Omega$, $10 \mathrm{k} \Omega$ resistors, a $1000 \mathrm{uF} / 25 \mathrm{~V}, 100 \mathrm{Uf} / 16 \mathrm{~V}$, capacitors, microcontrollers, voltage regulator, light emitting diode, transistors, buzzer, $16 * 2 \mathrm{LCD}$, crystal oscillator, 2-pin terminal block, power switch, 12 volts dc battery and $1 \mathrm{~kg}$ load sensor displayed in Figure 1.

*Corresponding AuthorEmail: waleisiro@yahoo.com; slinksjoy@gmail.com; daniella.eyeh@gmail.com

Tel: $+234-803-448-8877$ 


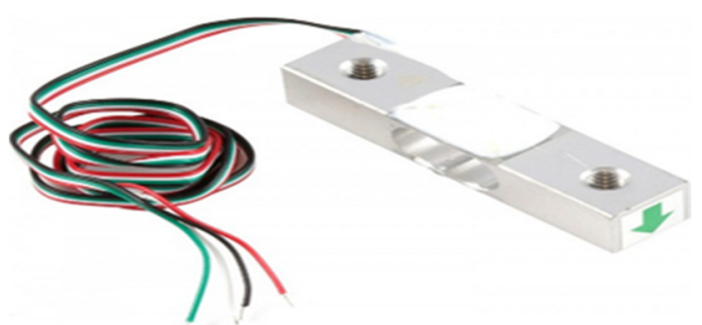

Fig 1: Load sensor

Design of Intravenous Monitoring System: The study considered technical approach to develop the automated infusion unit as the block diagram in Figure 2

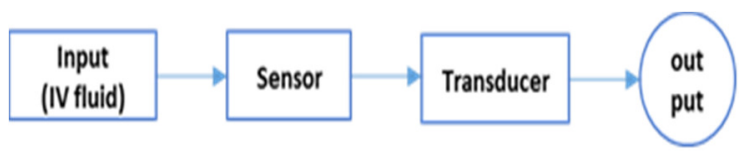

Fig 2: Block diagram for sensor

The design utilizes communication principles for data acquisition transmission within the remote system and receiving mode as revealed in Figure 3 and Figure 4. Laboratory setup of the device is as shown in Figure 5

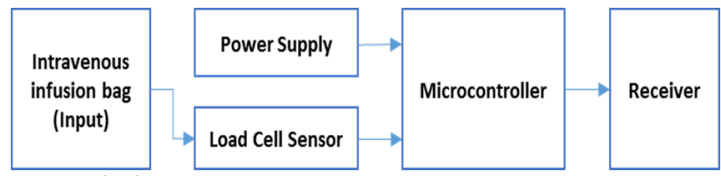

Fig 3: Block diagram for Transmitter at Node One

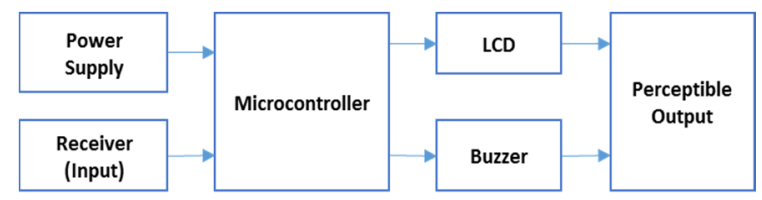

Fig 4: Block diagram for Receiver at Node two

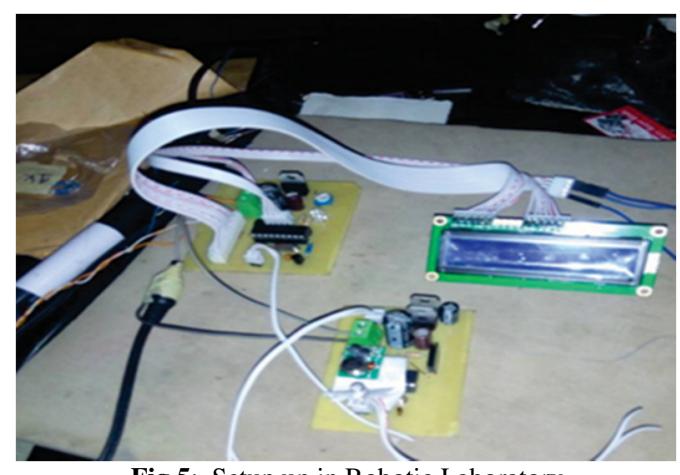

Fig 5: Setup up in Robotic Laboratory

Load Cell Principle of operation: A load cell is a transducer that measures force, and presents its output as an electrical signal. It features four strain gauges in a Wheatstone bridge configuration to detect measurements of resistance. Wheatstone bridge is an electrical circuit that balances two legs of a bridge circuit while the force being measured deforms the strain gauge in the load cell causing the deformation to be measured as change in electrical signal.

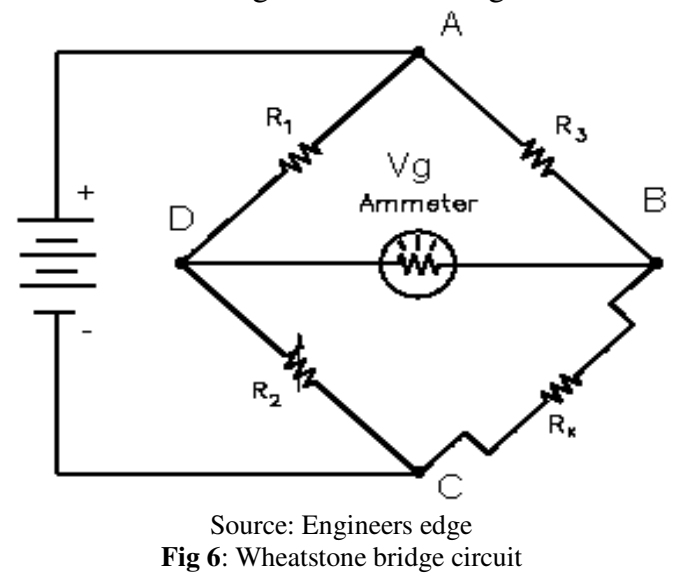

The load causes tension at the top of the gauge and relaxation at its bottom, producing a characteristic bending moment at the sides of the load cell. The force produced or exerted thus produces measurable electrical output that is proportional to the applied force acting on it. And the mathematical consideration for the Wheatstone Bridge Circuitry are as follows:

Given the Wheatstone bridge above, $\mathrm{R}_{2}$ is adjusted so that the ammeter reads zero current, then the resistance at both arms of the bridge circuit are equal, Alexander and Sadiku (2004). The equation guiding the relationship between the two arms of the bridge applies Kirchhoff's first rule to obtain the currents in junctions $\mathrm{B}$ and $\mathrm{C}$, and the Kirchhoff's second rule for finding voltage in the loops $\mathrm{ABD}$ and $\mathrm{BCD}$ :

$$
\begin{aligned}
& \frac{R_{1}}{R_{2}}=\frac{R_{3}}{R_{x}} \\
\rightarrow & R_{x}=\frac{R_{2} R_{3}}{R_{1}} \\
V_{G} & =\left(\frac{R_{x}}{R_{3}+R_{x}}-\frac{R_{2}}{R_{1}+R_{2}}\right) V_{S}
\end{aligned}
$$

Where $V_{G}$ is the voltage of node $\mathrm{B}$ relative to $\mathrm{D}$, all four resistors values and the supply voltage $V_{S}$ are known, the resistance of galvanometer is enough that its current is negligible. Since the resistance is directly proportional to the force, decrease in force leads to a corresponding decrease in the resistance of the load cell therefore;

$$
\begin{aligned}
& R \propto F \\
& R=Q F
\end{aligned}
$$

Where $Q$ is the rate of flow of volume.

$$
\begin{aligned}
& Q=V / t \\
& R=V F / t
\end{aligned}
$$


Therefore time (s) is given by

$$
\begin{aligned}
& t=V F / R \\
& \text { But } F=m a
\end{aligned}
$$

Considering mass (m) of intravenous fluid bag, at the commencement of its administration. Given that the mass of $1 \mathrm{ml}$ of saline fluid is $1.0046 \mathrm{~g}$ at $22^{\circ} \mathrm{C}$, thus, $500 \mathrm{ml}$ of a normal Saline is $502.3 \mathrm{~g}$ translating to $0.5023 \mathrm{~kg}$ of the drip bag. Applying third law of Newton, the force acting on the load sensor by 1 bag of IV fluid is $4.92254 \mathrm{~N}$, where acceleration due to gravity is $9.8 \mathrm{~ms}^{-2}$.

Suppose,

$$
t=0.05 F / R
$$

The time variations in resistance with drop in the weight of the IV bag as the content reduces is plotted using linear algebraic equation tool in MATLAB 2015a environment as shown in Figure 8(a) - (d).

\section{RESULTS AND DISCUSSION}

The final product of the study is displayed in Figure 7. Subjecting the device to functionality test, ten iterations were conducted but only three were chosen for discussion due to the consistence recorded in iterations 2 all through to 10 . Iteration 1 was carried out with full volume of the drip bag while the rest were done with volume of the drip bag remaining in the neighbourhood of the threshold value of $20 \mathrm{ml}$ to closely study the behavior of the modality within that range to satisfy reliability condition: the ability of a device to perform its required functions within the operational conditions. (Leitch, 1988).

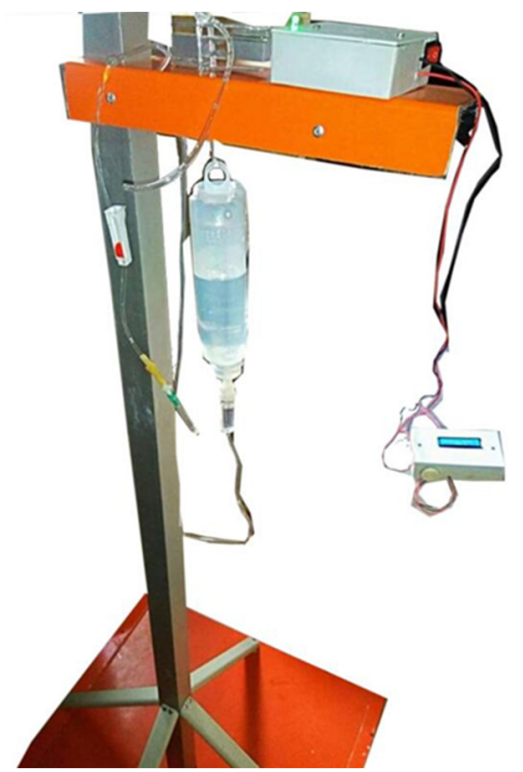

Fig 7: Automated alert system of an intravenous infusion system
Figure 8a is the outcome of the first iteration with full course of the drip bag. Observations were taken at threshold in all cases. Figures $8 \mathrm{~b}$ and $8 \mathrm{c}$ were repetition of the same procedure with the volume of the drip bag at threshold to ascertain precision and consistency in the operations of the modality. The rate of flow of intravenous fluid was substantially reduce during iterations 2 to 10 to ensure that buzzer was triggered at a precise time all through the nine iterations. And Figure 8d is the harmonization of three iterations of the same procedure performed under the same conditions but variable initial volume. The implication is that, irrespective of the initial volume of the drip bag, and the flow rate of intravenous fluid the operation of the modality is consistent since the three graphs collapse into a single graph. In medical practice, it is pertinent to monitor patient with respect to various medical procedures in the latter's healing process. When the system is subjected to load during iteration 1, the outputs are captured by steady declining graph.

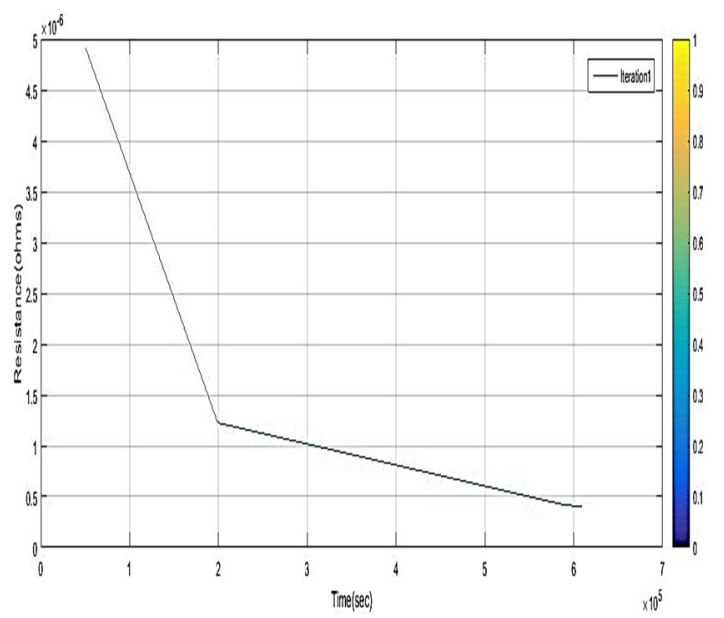

Fig 8a: Resistance variation with time for full volume of drip bag

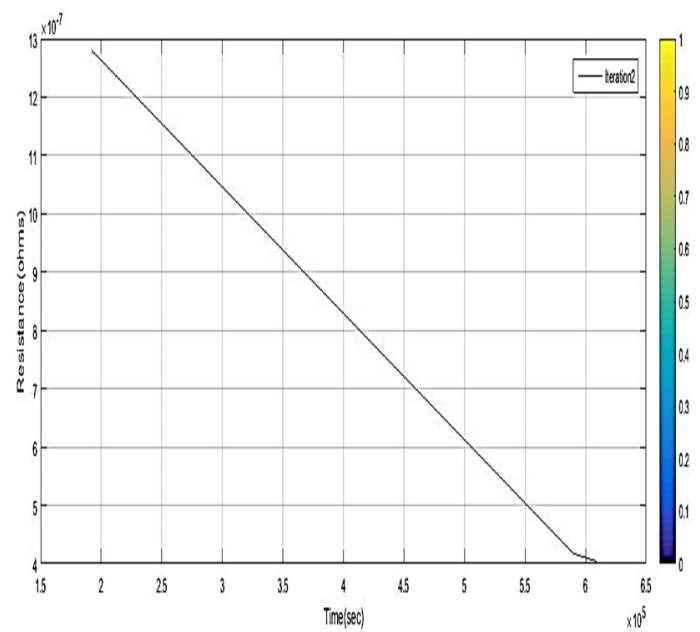

Fig 8b: Resistance variation with time for iteration 2 


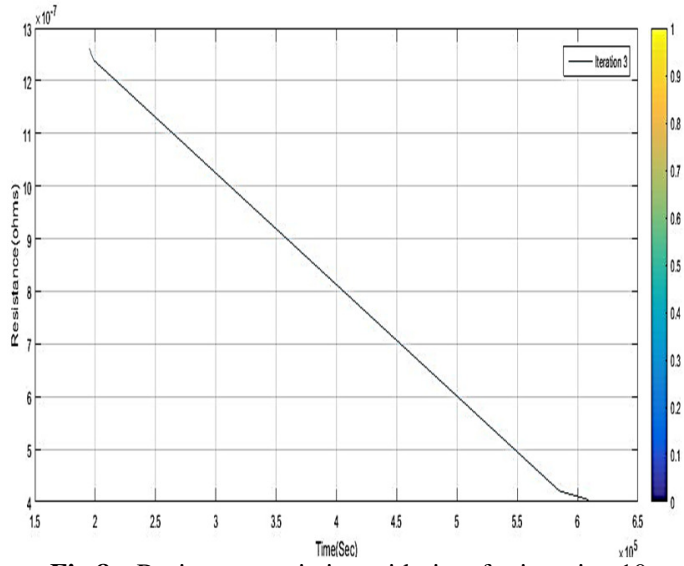

Fig 8c: Resistance variation with time for iteration 10

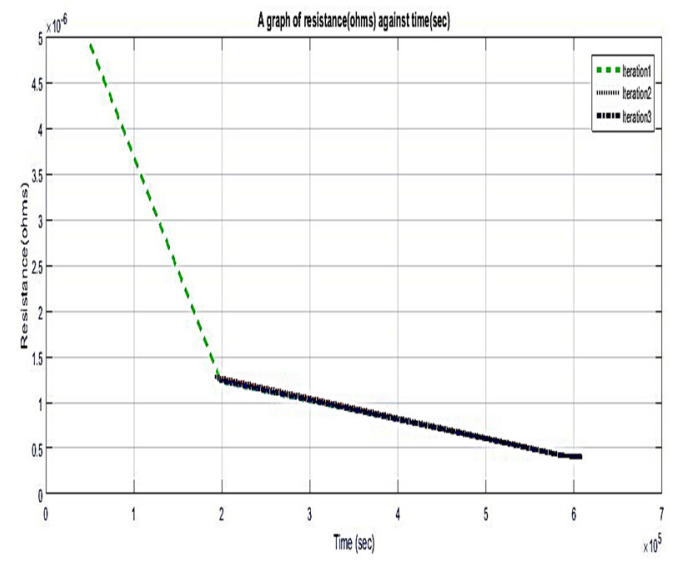

Fig 8d: Variation of resistance with time

The steepness in Figure 8a is radically reduced in the neighbourhood of time $t=2$ and below. There is sharp deviation in the slope of the outcomes which was calibrated as the alarm factor. The actual data were linearized to be able to record the sharp contrast at the threshold point where alarm is activated.

Various models in the literature have suggested wireless control network of the intravenous infusion system in contrast to the infusion pump which has the disadvantage of cost and sterilization to mention but a few (Batchelor, 1952; Engineers edge. (2018)). The design involving almost all the methods suggested, followed the same architecture, viz: the input which is the parameter to be measured; the sensor, which can either be optical, ultrasonic etc.; data transmission circuit, which may be a radio frequency transmitter and receiver, ZigBee micro-controller, GSM module, and the output. This study is in agreement with the works of Yang and Sun (2009) and Ziser et al (1979) among other scholarly studies. Considering various throwbacks and disadvantages of other modes of monitoring, the load cell offers more advantage with respect to sensitivity, precision and reproducibility.
The design of the modality presents strain created by IV fluid as tension to transducer that translates such into resistance. The resistance output is evaluated and processed for transmission to the final receiver node which receives input as current. As resistance decreases at transmission node, current increases at receiver node by Ohms law thereby causing the buzzer to trigger an alarm at attainment of threshold current.

Conclusion: This study considered the plight of critically ill patients who require intravenous intervention for medical patients' management and adequate monitoring by developing an automated modality for that purpose. All components deployed in building the modality are cheap and are also available locally in Nigeria, and the technology is repeatable. The device is maintainable and it is deployable to all strata of health sector: tertiary, secondary or primary.

\section{REFERENCES}

Ajibola, OOE; Folorunso, OP (2017). Analysis, design and construction of electronics ice cuff for athletes. Int. J. Med. Engr. Inform. 9(3): $220-$ 236.

Ajibola, OOE; Bolarinwa, O; Folorunso, OP; Balogun, O.J. (2018); Development of real time cardiographic sport utility vest for athletes. $J$. Assoc. Professional Engr. Trinidad \& Tobago. 46(1): 4-12.

Alexander, CK; Sadiku, MNO (2004). Fundamentals of electric circuit. McGraw-Hill, New York, USA.

Amano, H; Ogawa, H; Maki, H; Tsukamoto, S; Yonezawa, Y; Caldwell, WM (2012). A remote drip infusion monitoring system employing Bluetooth," 2012 Annual Int. Conf. IEEE Engr. Med. Biol. Soc., San Diego, CA, p. 2029-2032.

Batchelor, G. (1952). The effect of homogeneous turbulence on material lines and surface. Proc. Royal Soc. London, p. 349-366.

Dudde R; Vering T; Piechotta G; Hintsche, R. (2006). Computer aid continuous drug infusion; setup and test of a mobile closed-loop system for the continuous automation infusion of insulin.. IEEE Trans. Inf. Tech. Biomed. 2: 395-402.

Engineers edge. LLC (2018) Wheatstone bridge circuit equations and derivation. https://www.engineersedge.com. 
Gavimath, CC; Bhat, K; Chayalakshmi, CL; Hooli, RS; Ravishankera, BE (2012). Design and Development of versatile saline flow rate measuring system and GSM based remote monitoring device. Int. J. Pharm. Appl. 3(1): 277281.

Gordy S; Rowell S. (2013). Vascular air embolism. Gordy, S., and Rowell, S. (2013). Vascular air embolism. Int. J. Crit. Ill. \& Inj. Sci. 3: 73-76.

Hilton, AK; Pellegrino, VA; Scheinkestel, CD. (2008). Avoiding common problems associated with intravenous fluid therapy. Med J, 189(9): 509513.

Hoffmann, K. Wheatstone Bridge Circuit. Hottinger Baldwin Masstechnik $\mathrm{GmbH}$, Darmstadt.eln.teilam.gr/sites/default/files/Wheat stone\%20bridge.pdf.

Iyile, JE; Attah, SU. (2016). Design and construction of peripheral vein viewing device for intravenous administration of drug. PGD Thesis. University of Lagos, Lagos, Nigeria.

Kamble, VV; Pandey, PC; Gadgil, CP; Choudhary, DS. (2010). Monitoring of Intravenous Drip Rate. Proc. ICBME, India.

Kim, WH; Lee, S; Hwang, J. (2011). Real-time Energy Monitoring and Controlling System based onZigBee Sensor Network. Proc. Comp. Sci. 5: 794-797.

Kooijman, M. (2015). Building Wireless Sensor Networks Using Arduino. Packt Publishing, UK.

Leitch, RD. (1988). BASIC reliability engineering analysis. Butterworth and Co. (Publishers) Ltd, London.

Patel, S; Park, H; Bonato, P; Chan, L; Rodgers, M. (2012). A review of wearable sensors and systems with application in rehabilitation. J. NeuroEngr. Rehab.. 9: 21 - 38 .

Priyadharshini.R; Mithuna.S; Vasanth, KU; Kalpana, DS; Suthanthira, VN. (2015). Automatic Intravenous Fluid Level Indication. Int. J. Res. Appl. Sci. \& Engr. 3(1): 427 - 432.

Rangsee, P; Suebsombut, P; Boonyanant, P. (2014). Low-cost saline droplet measurement system using for common patient room in rural public hospital. Information and Communication Technology, Electronic and Electrical Engineering, 4th Joint Int. Conf. Chiang Rai, p. 15.

Robert, SW. (2010). The link between intravenous multiple pump flow errors and infusion system mechanical compliance Murphy. Anesth. Analog, 110(5): 1297-1302.

Simon, N. (2010). Impact of infusion method on amikacin serum levels in humans. Pulm. Pharma. Therap, 23(4): 324-326.

Stephens, K.R. 2013. The impact of evidence-based practice in nursing and the next big ideas. Online J. Iss. Nur. 18(2): 4.

Wheeler (2007). Commercial applications of wireless sensor networks using ZigBee. IEEE Comm. Mag. 45(4): 70-77.

Yadav, S; Jain, P. (2016). Real-time cost-effective esaline monitoring and control system. 2016 Int. Conf. Control Comp. Comm. Mat. p. 1.

Yang, W; Sun, L. (2009). A Novel Medical Infusion Monitoring System. Proc. 2009 Int. Symp. Web Info. Sys. Appl. p. 291-293.

Ziser, M; Feezor, M; Skolaut, MW. (1979). Regulating intravenous fluid: controller versus clamps. Am. J. Hosp. Pharm, 36(8): 1090-1094. 